\title{
TITLE:
}

\section{$<$ Obituary> Professor Shigeo Uehara : Member of the Mahale Wildlife Conservation Society}

AUTHOR(S):

Nishida, Toshisada

\section{CITATION:}

Nishida, Toshisada. <Obituary> Professor Shigeo Uehara: Member of the Mahale Wildlife Conservation Society. Pan Africa News 2005, 12(1):

$2-3$

ISSUE DATE:

2005-06

URL:

http://hdl.handle.net/2433/143452

RIGHT:

Copyright (C) Pan Africa News. 


\section{OBITUARY}

\section{Professor Shigeo Uehara: Member of the Mahale Wildlife Conservation Society}

Toshisada Nishida

Japan Monkey Centre

Professor Shigeo Uehara (Uehara-san) sadly passed away on the morning of August 24, 2004, at only 58 years old. Uehara-san was my closest colleague in the Mahale Mountains Chimpanzee Research Project and simultaneously one of my most reliable friends.

Uehara-san's important contributions to the study of chimpanzees include the followings: $\mathrm{He}$ found that K-group chimpanzees exploit termites belonging to the genus Pseudocanthotermes by different techniques in accordance with the termite life cycle -- fishing for soldiers at the beginning of the rainy season, catching winged termites with their hands at the end of the rainy season, and taking termite soils all year round.

He was most interested in the origins of division of labor by sex, and sought to examine sex and age differences in chimpanzee subsistence behavior. He found that male chimpanzees are engaged more in predatory behavior and females more in eating ants. Furthermore, he clarified that adult males ingest piths of grasses significantly faster than adolescent males. Moreover, by comparison with the data from Gombe and Tai, he clarified the characteristics of predatory behavior

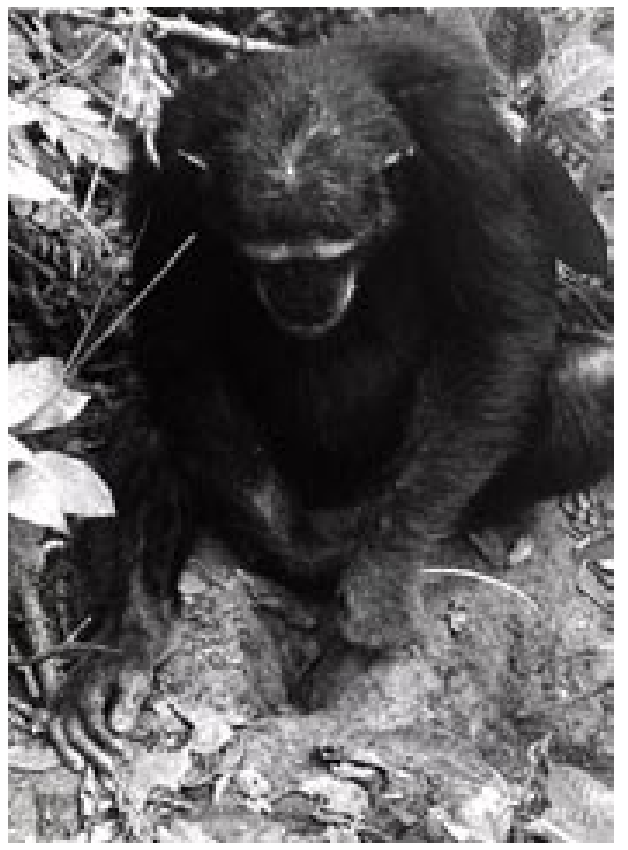

Photo 2. Wantangwa, a K-group female, puts her bark probe into the nest of Pseudacnthotermes spiniger (photo by S. Uehara).

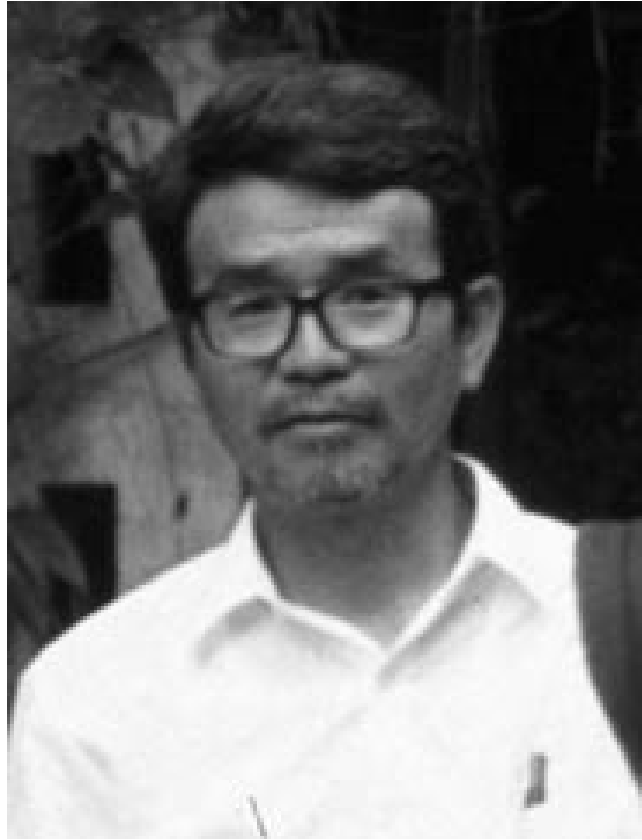

Photo 1. Uehara-san in 2002

displayed by chimpanzees at Mahale.

He took the body weight of chimpanzees and derived an interesting conclusion that the chimpanzees of Gombe are significantly smaller than those of Mahale although they belonged to the same subspecies. He explained this local difference by the less nutritional diet at Gombe, which is ultimately a result of differences in vegetation. Ecologically important is his finding that body weights reach their minimum in the middle of the rainy season, which is congruent with the recent finding from phenological research that fruit production is lowest at Mahale during this season.

Uehara-san also made an important contribution to the understanding of chimpanzee social organization. He concluded that the chimpanzee social unit is a bisexual group, rejecting the maleonly unit hypothesis. This conclusion was drawn after a detailed analysis of long-term data on female transfer and association patterns of males and females. He examined examples of defeated alpha males who were ostracized by other adult males and concluded that only the ex-alpha males that can maintain the social nexus with some other adult males when living a lonely life can return to the unit group. He also reported a heart-warming episode in which an unrelated female adopted a male infant when his mother was suffering from illness. After a week she returned the charge to the recovered mother.

Uehara-san's contribution to the Mahale study includes the most basic part of research such as compilation of both a Tongwe-Latin dictionary of plants and the list of chimpanzee food plants, 


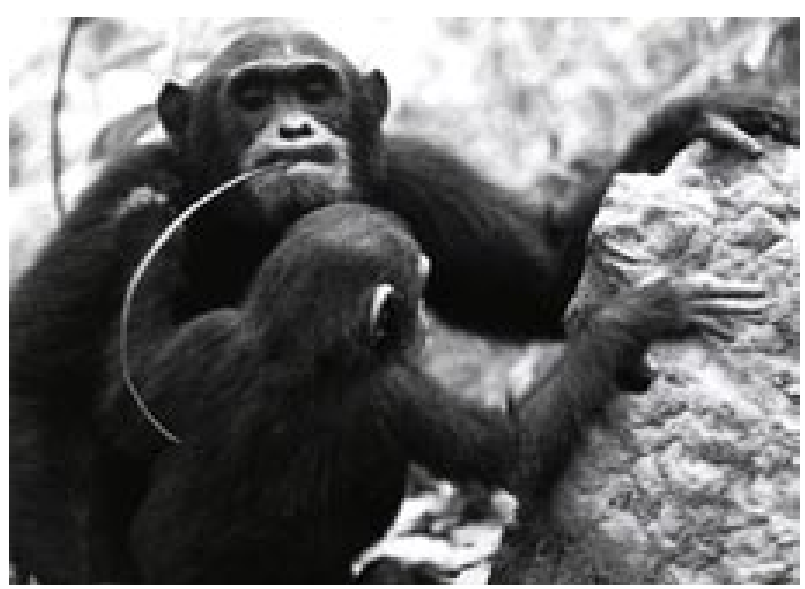

Photo 3(right). Chausiku and her son Katabi hold the termite hill of P. spiniger. Chausiku has a bark probe in her mouth (photo by S. Uehara).

which was based on his excellent knowledge of botany and systematics. It should not be forgotten that Uehara-san played a crucial role in the initial study of $M$ group, particularly in the individual identification and christening of many adult females and immature chimpanzees in 1973. With considerable dedication by Mariko HiraiwaHasegawa, Toshikazu Hasegawa and Kenji Kawanaka to this venture, his effort formed the basis of the long-term research that is continuing through many researchers and students.

Uehara-san's research career was not limited to Mahale. He studied the ecology of bilias (bonobos) in the swamp of Yalosidi, and found that swamp was used by two antagonistic unit groups of bilias to feed for 8 species of aquatic plants. He was one of the first scientists to observe that bilias mated in the ventro-ventral position while the female was literally wet in the shallow water. His masters thesis focused on the temperate components of food composition of Japanese macaques. From detailed analyses he hypothesized that Japanese macaques had migrated to Japan via the western (Korean) route

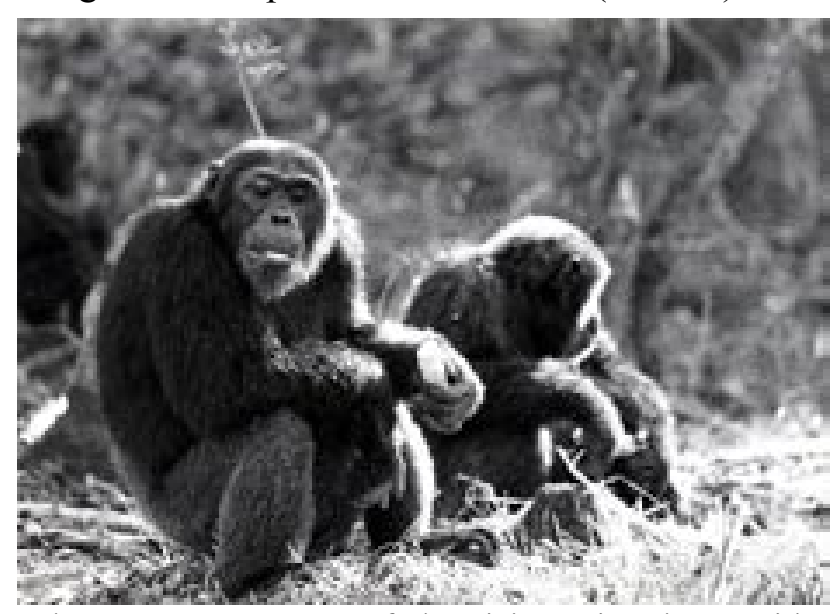

Photo 4. Kasonta, one of the alpha males that could return to the alpha position after having been ostracized (photo by S. Uehara). from the Asian continent and moved northward.

Uehara-san was so warm, kind and mild in his character that he was loved and respected by all those who knew him. One of the most interesting aspects of his character was that he was fastidious about fieldwork preparation. Before setting out into the bush in the morning, he would thoroughly check all his belongings, ranging from his binoculars and field notes to his compass and colored pencils.

For more than five years Uehara-san had expressed his desire to visit Mahale with his wife, son and daughter. I am deeply sad that he could not realize his dream.

Uehara-san will be greatly missed by all who knew him and worked with him. 